\title{
Measuring the Efficiency of Regional Entrepreneurship Systems - An Application of Dynamic Network DEA on Taiwan's Counties and Cities
}

\author{
Chih Cheng Chen ${ }^{1, *}$ \\ ${ }^{1}$ Department of Information Management, Yuan Ze University \\ No. 135, Yuan-dong Road, Chungli District, Taoyuan City, Taiwan \\ E-mail: < chihcheng@saturn.yzu.edu.tw>
}

\begin{abstract}
In this study, we apply dynamic network data envelopment analysis with slack-based measures to estimate the degree of ease of doing business in Taiwan's counties and cities from 2004 to 2012. By proposing a three-stage regional entrepreneurship system, including entrepreneurship, survival, and operation stages in each county and city in Taiwan, we calculate not only the overall efficiency of the whole system, but also the stage efficiencies, the period efficiencies, and the stage efficiencies in each period. Our findings indicate that the average overall efficiency of Taiwan's regional entrepreneurship system is higher in urban areas than in rural areas; while the average stage efficiency in operation stage is improving, its average efficiency in every year is better in urban than in rural areas. We also find dynamic self-effects in the entrepreneurship system of Taiwan's counties and cities. The implications of this study indicate that entrepreneurs should locate their new enterprises in urban areas in Taiwan, due to the higher efficiencies of their entrepreneurship systems and better environments for business operation; as for local governments in rural areas, the improvement of their entrepreneurship environment is necessary, especially for the performance at operation stage.
\end{abstract}

Keywords: regional entrepreneurship system, dynamic network DEA, slack-based method, urban-rural gap, dynamic self-effect.

Received: October 2, 2017; accepted: July 8 2018; available online: July 24; 2018

DOI: $10.17535 /$ crorr.2018.0010

\section{Introduction}

The importance of entrepreneurial activity does not have to be emphasized today, although many years have passed since Schumpeter argued that innovation and technological change in a nation come from its entrepreneurs or "wild spirits" [15]. The Entrepreneurship at a Glance 2016 survey released by the Organization for Economic Co-operation and Development argues that a revival in entrepreneurial activity not only helps to improve economic growth, but can also provide an important longer-term boost to productivity, given the positive link between start-up rates and productivity growth [12]. Thus, to measure the level of entrepreneurial activity in a country or region is important, because it provides a crucial index for the estimation of future economic development. 
However, measuring the level of entrepreneurial activity in a country/region should not consider entrepreneurship alone, but also the abilities and possibilities for business survival and the production level of operations. In other words, to investigate the level of entrepreneurial activity in a country/region, we should not consider it from the perspective of entrepreneurship only, but from the perspective of the whole entrepreneurship system, which includes the entrepreneurship, survival, and operation stages. The method used to measure the level of functioning of the whole entrepreneurship system is another important issue. It would also be better to measure the active level of the capabilities of an entrepreneurship system both from an overall perspective and simultaneously during each stage of the business process in a country or region. To meet these considerations, we need to employ a method that can deal with all these requirements at the same time.

In this study, we will apply a dynamic slack-based model (SBM) of data envelopment analysis (DEA) with a network structure to measure the active degree of entrepreneurial activity in a region. If a region has a better environment for entrepreneurial activity, it will attract more start-ups based on the same inputs for entrepreneurship. Then, a country or region that is more active in entrepreneurial activity could be taken as a location with higher efficiency for entrepreneurship. From this consideration, we can borrow the concept of efficiency in a DEA model to capture the active level of entrepreneurial activity in a region. Originally, the model were called network DEA models $[7,19]$, while the augmented approach is known as dynamic DEA [17]. Furthermore, Tone and Tsutsui [18] combined these two concepts into an integrated analytical framework, describing their model as dynamic DEA with network structure. Avkiran [2]calls this approach dynamic network DEA. In this study, we employ the dynamic network DEA approach to evaluate the entrepreneurship system in Taiwan's counties and cities in the period 2004-2012. Our calculated results indicate that the average overall efficiency of Taiwan's regional entrepreneurship system is higher in urban areas than in rural areas; while the average stage efficiency at operation stage is higher after 2008. Finally, the average efficiency at operation stage is better in in urban areas than in rural areas. The remaining parts of the present work are as follows: the review of literature on the dynamic network DEA model is in section 2 ; section 3 shows the proposed analytical framework applied in this study; section 4 describes the variables selected in each stage, their processing methods, and the basic descriptive statistics; section 5 presents the empirical results of our model; and section 6 concludes with the final discussion.

\section{Literature review: dynamic network DEA}

The SBM approach of dynamic network DEA was first proposed by [18]. They put forward a model involving network structure in each period within the framework of a slack-based measure approach, which formed a composite of their two existing models, designated as network SBM (NSBM) [19] and dynamic SBM (DSBM) [17] respectively.

As for applications of the dynamic network DEA model, Avkiran [2] illustrate it in commercial banking with an emphasis on testing robustness. The paper also discusses discrimination by efficiency estimates, dimensionality of the performance model, stability of estimates through resampling, and sensitivity of results to divisional weights and returns-to-scale assumptions under robustness testing. Bai et al. [3] evaluate the performance of national hi-tech zones (HTZs) in China after the financial crisis by employing a dynamic network slack-based measure, which 
supposes that the HTZs in China form a network and are connected by carry-overs between sequenced terms and links among different sectors. The results show that the efficiencies of both production sectors and R\&D sectors are low in most Chinese HTZs.

Olfat et al. [13] consider the sustainability of airports through a multi-perspective, multisystem, and multi-process operation, applying a fuzzy dynamic network performance measurement approach to the determination of the efficiency performance of an airport system. The results indicate that the main current problem of most Iranian airports is related to their relationships with the community. Chang et al. [5] also develop a novel dynamic network DEA framework to investigate the substitutability between the passenger facility charge (PFC) and airport improvement program (AIP) funds, the two major sources of finance for U.S. airports.

As for other fields, Herrera-Restrepo et al. [9] consider evacuation planning as a multiperspective, multi-system, and multi-process operation, and apply a dynamic network performance measurement approach to measure the efficiency performance of this system of systems. Omrani and Soltanzadeh [14] proposes a relational dynamic NDEA (DNDEA) model that simultaneously measures the efficiencies of the system and its internal processes over time. The results show that the consumption stage is more efficient than the production stage for Iranian airlines. The low overall efficiency scores for the airlines' system are due to the poor performance in the production stage. Finally, Khushalani and Ozcan [11] examine the efficiency of quality production in hospitals using dynamic network DEA and identifying the hospital characteristics that contribute to this efficiency. Their findings show that the efficiency of quality production improved significantly in the research period. Urban and teaching hospitals were less likely to improve the efficiency of quality production.

The discussion above shows that there are still only a few existing applications of the dynamic network DEA model. Besides Bai et al. [3], related to the regional efficiency of HTZs in China, no one has investigated regional entrepreneurship systems. The present study is thus the first to extend the application of dynamic network DEA to studies on regional efficiency.

\section{Methodology}

\subsection{Conceptual Framework of Regional Entrepreneurship Systems}

We propose a conceptual framework of the regional entrepreneurship system in a Taiwanese county or city for two succeeding periods in Figure 1. There are three stages in this system, including entrepreneurship, survival, and operation. Our concerns regarding this system are as follows:

1. An officer in the department of economic affairs has the objective of attracting more investments, creating more employment, helping families to earn higher incomes, and offering better living environments and standards for the inhabitants.

2. For the first two objectives, the system has to create an environment for entrepreneurs not only to start and develop their own businesses effectively for survival and sustainability, but also to operate smoothly and create more production values going forward. 
3. If the economic environment in a county or city is more efficient, it will attract more entrepreneurial activities, involving more investment and higher demand for labor, and thus generating more employment and production outputs. Therefore, we include entrepreneurship, survival, and operations in the system.

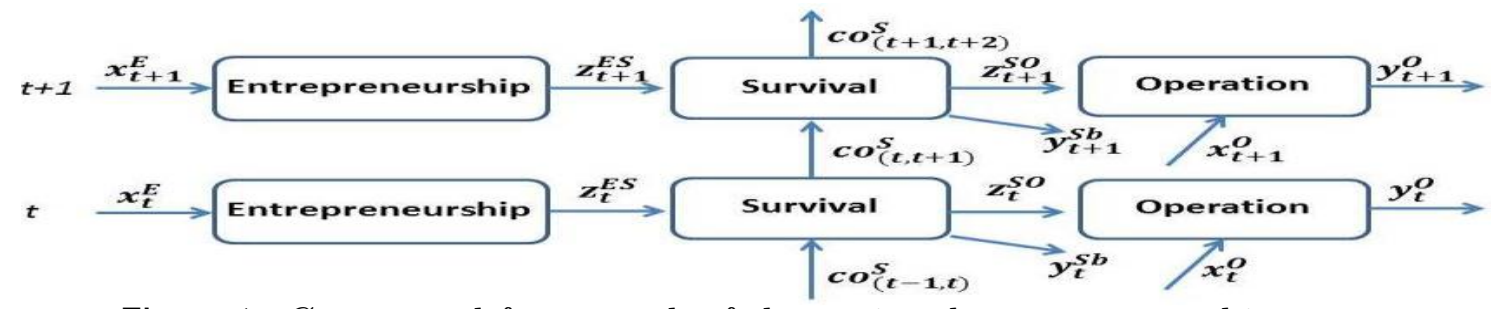

Figure 1: Conceptual framework of the regional entrepreneurship system

In Figure $1, x_{t}^{E}\left(x_{t+1}^{E}\right)$ is the input vector of entrepreneurship stage at time $\mathrm{t}(\mathrm{t}+1) ; z_{t}^{E S}\left(z_{t+1}^{E S}\right)$ and $z_{t}^{S O}\left(z_{t+1}^{S O}\right)$ are the output vectors of the entrepreneurship and survival stages and the inputs of the survival and operation stages respectively -in other words, they are the intermediate variables between two stages, these relations between two stages being called links in Tone and Tsutsui [18]; $x_{t}^{O}\left(x_{t+1}^{O}\right)$ is the input vector of the operation stage at time $\mathrm{t}(\mathrm{t}+1)$; $y_{t}^{O}\left(y_{t+1}^{O}\right)$ is the output vector of the operation stage at time $\mathrm{t}(\mathrm{t}+1) ; \cot _{t, t+1}^{S}\left(\operatorname{co}_{t+1, t+2}^{S}\right)$ is the vector of carry-over variables that connect the survival stage in successive periods $t(t+1)$; finally, we also assume that undesirable outputs exist in the survival stage, these being denoted as $y_{t}^{S b}\left(y_{t+1}^{S b}\right)$.

\subsection{Expression for County/City $o$}

The condition of county/city $o(o=1,2, \ldots N) \in P^{t}$ can then be expressed as follows. First, we define the input and output constraints of county/city $O$ as:

$$
\begin{gathered}
\sum_{i=1}^{N} \lambda_{i g t}^{E} x_{i g t}^{E}=x_{o g t}^{E}-s_{o g t}^{E}(\forall g, \forall t), \quad \sum_{i=1}^{N} \lambda_{i j t}^{S} y_{i j t}^{S b}=y_{o j n}^{S b}-s_{o j n}^{S b}(\forall j, \forall t), \\
\sum_{i=1}^{N} \lambda_{i r t}^{O} x_{i r t}^{O}=x_{o r t}^{O}-s_{o r t}^{O}(\forall r, \forall t), \quad \sum_{i=1}^{N} \lambda_{i h t}^{O} y_{i h t}^{O}=y_{o h t}^{O}+s_{o h t}^{O}(\forall h, \forall t), \\
\sum_{i=1}^{N} \lambda_{i g t}^{E}=1(\forall t), \sum_{i=1}^{N} \lambda_{i j t}^{S}=1(\forall t), \sum_{i=1}^{N} \lambda_{i r t}^{O}=1(\forall t), \sum_{i=1}^{N} \lambda_{i h t}^{O}=1(\forall t), \\
\lambda_{i g t}^{E} \geq 0(\forall g, \forall t), \quad \lambda_{i j t}^{S} \geq 0(\forall j, \forall t), \lambda_{i r t}^{O} \geq 0(\forall r, \forall t), \lambda_{i h t}^{O} \geq 0(\forall h, \forall t), \\
s_{o g t}^{E} \geq 0(\forall g, \forall t), s_{o j n}^{S b} \geq 0(\forall j, \forall t), s_{o r t}^{O} \geq 0(\forall r, \forall t), s_{o h t}^{O} \geq 0(\forall h, \forall t), i=1,2, \ldots N,(1)
\end{gathered}
$$

where $P^{t}, s_{o g t}^{E}, s_{o j n}^{S b}, s_{o r t}^{O}$, and $s_{o h t}^{O}$ are the production possibility set and slacks, respectively. As for the links, Tone and Tsutsui[18] mention four cases, these being the free link, nondiscretionary fixed link, as-input link, and as-output link. However, Tone and Tsutsui [19] and Kao [10] consider slacks of intermediate products - while determining efficiency scores through the inequality settings on the constraints of intermediate products - by adding the slacks and including them into the subjective function. Thus, we apply their settings in the constraints on links of county/city $\boldsymbol{o}$. They are as follows:

$$
\begin{array}{lll}
\sum_{i=1}^{N} \lambda_{i k t}^{E} z_{i k t}^{E S}=\sum_{i=1}^{N} \lambda_{\text {ikt }}^{S} z_{\text {ikt }}^{E S}(\forall t), & & \sum_{i=1}^{N} \lambda_{\text {ilt }}^{S} z_{\text {ilt }}^{S O}=\sum_{i=1}^{N} \lambda_{\text {ilt }}^{O} z_{\text {ilt }}^{S O}(\forall t), \\
\sum_{i=1}^{N} \lambda_{\text {ikt }}^{E} z_{\text {ikt }}^{E S}=z_{\text {okt }}^{E S}+s_{\text {okt }}^{E S+}(\forall k, \forall t), & \sum_{i=1}^{N} \lambda_{\text {ikt }}^{S} z_{\text {ikt }}^{E S}=z_{\text {okt }}^{E S}-s_{\text {okt }}^{E S-}(\forall k, \forall t), \\
\sum_{i=1}^{N} \lambda_{\text {ilt }}^{S} z_{\text {ilt }}^{S O}=z_{\text {olt }}^{S O}+s_{\text {olt }}^{S O+}(\forall l, \forall t), & \sum_{i=1}^{N} \lambda_{\text {ilt }}^{O} z_{\text {ilt }}^{\text {SO }}=z_{\text {olt }}^{S O}-s_{\text {olt }}^{S O-}(\forall l, \forall t),
\end{array}
$$




$$
\begin{aligned}
& \sum_{i=1}^{N} \lambda_{i k t}^{E}=1(\forall t), \quad \sum_{i=1}^{N} \lambda_{\text {ikt }}^{S}=1(\forall t), \sum_{i=1}^{N} \lambda_{\text {ilt }}^{S}=1(\forall t), \quad \sum_{i=1}^{N} \lambda_{\text {ilt }}^{O}=1(\forall t), \\
& s_{\text {okt }}^{E S+} \geq 0(\forall k, \forall t), s_{\text {okt }}^{E S-} \geq 0(\forall k, \forall t), \quad s_{\text {olt }}^{S O+} \geq 0(\forall l, \forall t), \quad s_{\text {olt }}^{\text {SO- }} \geq 0(\forall l, \forall t),
\end{aligned}
$$

where $s_{\text {okt }}^{E S+}, s_{\text {okt }}^{E S-}, s_{\text {olt }}^{S O+}$, and $s_{\text {olt }}^{\text {SO- }}$ are the respective slacks.

Finally, as for carry-over activities, Tone and Tsutsui [18] also mention four categories, these being desirable (good), undesirable (bad), discretionary (free), and non-discretionary (fixed) carry-overs. In this study, our carry-over variables are the total number of firms and the total amount of registered capital at the survival stage. We assume that they are good for a county/city for its future economic development; thus, we treat them as the desirable (good) carry-over case.

According to Tone and Tsutsui [18], desirable carry-overs are treated as outputs and their values are restricted to be not less than the observed one. A comparative shortage of carryovers in this category is counted as inefficiency. Thus, the constraints on the carry-over variables in this study are as follows:

$$
\begin{aligned}
& \sum_{i=1}^{N} \lambda_{i m t}^{S} c o_{i m(t, t+1)}^{S}=\sum_{i=1}^{N} \lambda_{i m t+1}^{S} c o_{i m(t, t+1)}^{S}(\forall m, t=1,2, \ldots, T-1), \\
& \sum_{i=1}^{N} \lambda_{i m t}^{S} c o_{i m(t, t+1)}^{S}=c o_{o m(t, t+1)}^{S}+s_{o m(t, t+1)}^{S}(\forall m, \forall t), \\
& \sum_{i=1}^{N} \lambda_{i m t}^{S}=1(\forall t), \quad \sum_{i=1}^{N} \lambda_{i m t+1}^{S}=1(\forall t), \quad s_{o m(t, t+1)}^{S} \geq 0(\forall m, \forall t),
\end{aligned}
$$

where $s_{o m(t, t+1)}^{S}$ is the vector of slacks for carry-over activities.

Finally, Tone and Tsutsui [18] also mention the constraints of the initial carry-overs $(t=0)$. Because they are assumed given and fixed, their constraints can be expressed as

$$
\sum_{i=1}^{N} \lambda_{i m 1}^{S} \operatorname{co}_{i m(0,1)}^{S}=c o_{o m(0,1)}^{S} .
$$

\subsection{The Objective Functions}

This section deals with the overall, period, and divisional efficiencies in the case of the nonoriented model. The overall efficiency for unit $o$ is evaluated by the following expression:

$$
\begin{aligned}
& \theta_{0}^{*}=
\end{aligned}
$$

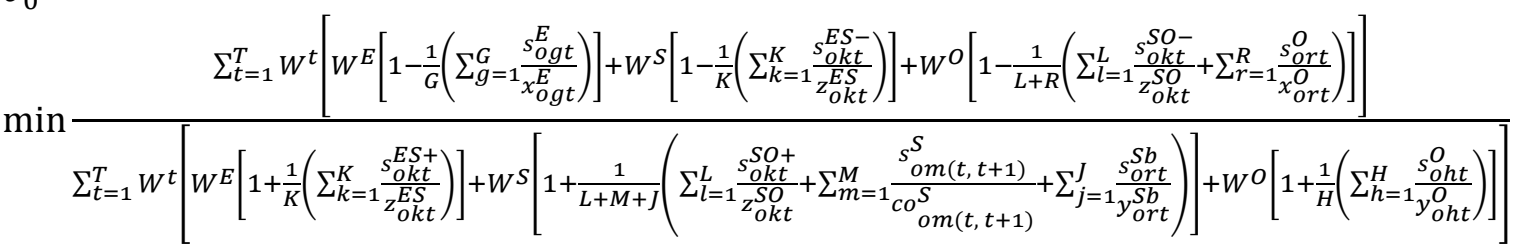

subject to conditions $(2)-(5)$, where $W^{t}(\forall \mathrm{t})$ is the weight to period t and $W^{E}, W^{S}$, and $W^{O}$ are the weights to entrepreneurship, survival, and operation stages, respectively. These weights satisfy the condition: $\sum_{t=1}^{T} W^{t}=1, W^{E}+W^{S}+W^{O}=1, W^{t} \geq 0(\forall t), W^{E} \geq 0, W^{S} \geq 0$, $W^{O} \geq 0$. They are supplied exogenously [18]. This objective function revises the slack-based measure (SBM) developed in Tone [16]. The weights $W^{E}, W^{S}$, and $W^{O}$ indicate the importance of each stage, while the period weights $W^{t}$ could reflect, for example, discount rate by period. The conditions $\theta_{0}^{*} \leq 1$ and $\theta_{0}^{*}=1$ hold if and only if all slacks are zero [18]. The input- 
(output-) oriented model can be defined by dealing with the numerator (denominator) of the above objective function.

Utilizing the optimal slacks obtained by solving the program (6), we define period efficiency of county/city $o$ as follows:

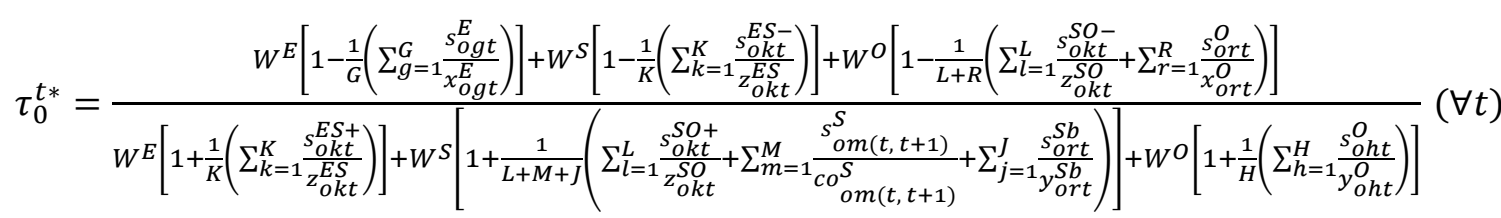

The efficiency at entrepreneurship stage of county/city $o$ is defined by

$$
\delta_{0}^{E *}=\frac{\sum_{t=1}^{T} W^{t}\left[1-\frac{1}{K}\left(\sum_{k=1}^{K} \frac{s_{\text {okt }}^{E S-}}{z_{\text {okt }}^{E S}}\right)\right]}{\sum_{t=1}^{T} W^{t}\left[1+\frac{1}{K}\left(\sum_{k=1}^{K} \frac{s_{\text {okt }}^{E S+}}{z_{\text {okt }}^{E S}}\right)\right]}
$$

The efficiency at survival stage of county/city $o$ is defined by

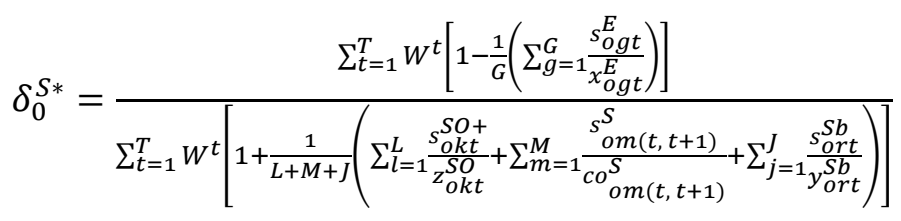

The efficiency at operation stage of county/city $o$ is defined by

$$
\delta_{0}^{O *}=\frac{\sum_{t=1}^{T} W^{t}\left[1-\frac{1}{L+R}\left(\sum_{l=1}^{L} \frac{S_{\text {okt }}^{S O-}}{\left.\left.z_{\text {okt }}^{S O}+\sum_{r=1}^{R} \frac{s_{o r t}^{O}}{x_{o r t}^{O}}\right)\right]}\right.\right.}{\sum_{t=1}^{T} W^{t}\left[1-\frac{1}{H}\left(\sum_{h=1}^{H} \frac{s_{\text {oht }}^{O}}{y_{o h t}^{O}}\right)\right]}
$$

The efficiency at entrepreneurship stage of county/city $o$ at time t is defined by

$$
\rho_{0}^{E t *}=\frac{1-\frac{1}{K}\left(\sum_{k=1}^{K} \frac{s_{o k t}^{E S-}}{z_{o k t}^{E S}}\right)}{1+\frac{1}{K}\left(\sum_{k=1}^{K} \frac{s_{o k t}^{E S+}}{z_{o k t}^{E S}}\right)}
$$

The efficiency at survival stage of county/city $o$ at time $t$ is defined by

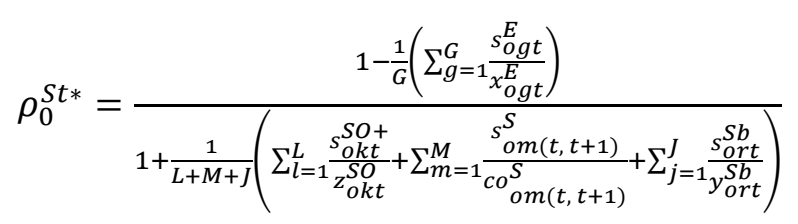

The efficiency at operation stage of county/city $o$ at time $\mathrm{t}$ is defined by

$$
\rho_{0}^{O t *}=\frac{1-\frac{1}{L+R}\left(\sum_{l=1}^{L} \frac{{ }_{\text {okt }}^{S O-}}{\left.z_{o k t}^{S O}+\sum_{r=1}^{R O} \frac{s_{o r t}^{O}}{x_{o r t}^{O}}\right)}\right.}{1+\frac{1}{H}\left(\sum_{h=1}^{H} \frac{s_{o h t}^{O}}{y_{o h t}^{O}}\right)}
$$

Finally, Tone and Tsutsui [18] mentioned that, although the overall efficiency is uniquely determined by evaluating expression (5), slacks are not necessarily unique. Hence, the period efficiency in (6) may suffer from non-uniqueness issues. To solve this problem, they proposed to solve the period efficiency at time $\mathrm{T}$ first, because it would be reasonable to consider that the last period $\mathrm{T}$ has top priority and those of $\mathrm{T}-1, \mathrm{~T}-2, \ldots, 1$ decrease in this order. In calculating the efficiency value of county/city $o$ at time $\mathrm{T}$, the minimization of (6) should satisfy 
constraints (1)-(4) and the optimal values of (5) at the same time. Then the calculation of optimal period efficiency $\mathrm{T}-1$ should simultaneously satisfy constraints (1)-(4) and the optimal values of (5) and the optimal period efficiency at time T. By applying this scheme in calculating the optimal period efficiency to other periods year by year, Tone and Tsutsui [18] point out that the non-uniqueness problem can be solved. Thus, we also apply this scheme in this study.

\section{The Variables}

To evaluate the overall and divisional performances of the economic administration system in Taiwan's counties and cities, we use the data provided by the Directorate General of Budget, Accounting, and Statistics in Taiwan's Executive Yuan on the website "Inquiry System for Counties'Cities' Important Indicators" (ISCII) from 2004-2012. In this section we introduce the variables used for each stage. Finally, as the DMUs in this study are Taiwan's counties and cities, all the variables represent aggregated data on the basis of county/city to ensure the internal consistency of these indicators.

\subsection{Variables for the Entrepreneurship Stage}

In this stage, we employ the "number of workforce" (in thousands) and "yearly expenses for economic development" as inputs and the "number of new companies registered" and the "number of self-employed individuals" (in thousands) as the output variables. The workforce numbers, yearly expenses for economic development, and new companies registered are collected directly from the ISCII website. The number of self-employed individuals (in thousands) is calculated by multiplying the number of those in employment (in thousands) by the ratio of self-employed individuals (\%). The numbers of new companies registered and selfemployed individuals both represent desirable outputs in this stage and form the input variables of the sustainability stage. We also employ part of the shared input, the yearly expenses for economic development (billion TWD), as another input variable (available on the ISCII website).

\subsection{Variables for the Survival Stage}

As mentioned in section 4.1, the input variables in this stage are "number of new companies registered" and "self-employed individuals." As for the desirable output, we adopt "number of employees" in this study. This is also one of the inputs at operation stage. In addition, we also employ the number of company dissolutions, revocations, and terminations (NCDRT) as a variable denoting undesirable outcomes. For the carry-overs, we employ "number of registered companies" and "total registered capital." All of these variables are available on the ISCII website.

\subsection{Variables for the Operation Stage}

In this stage, the outcome of the sustainability stage, i.e., "number of employees," is one of the inputs. We also employ "total consumption of electricity" as another input in this stage. For the output for this stage, the "total amount of business sales" is employed. The reasons for 
considering "number of employees" and "total consumption of electricity" as the inputs of this stage are straightforward, because they are necessary inputs used to produce the outputs of the firms. Finally, their products and services manifest their values when sold, thus we employ the "total amount of business sales" as the output variable at this stage. Table 1 shows the descriptive statistics for the variables used in this study.

\begin{tabular}{|l|r|r|r|r|r|}
\hline \multicolumn{1}{|c|}{ Variable } & Obs & \multicolumn{1}{c|}{ Mean } & Std. Dev. & \multicolumn{1}{c|}{ Min } & \multicolumn{1}{c|}{ Max } \\
\hline $\begin{array}{l}\text { Yearly expenses for economic development } \\
\text { (million TWD) }\end{array}$ & 180 & 6869.272 & 6882.961 & 823.890 & 41714.860 \\
\hline Number of workforce (in thousands) & 180 & 541.761 & 507.264 & 35.000 & 1993.000 \\
\hline Number of new companies registered & 180 & 1897.472 & 2791.993 & 22.000 & 12818.000 \\
\hline Number of self-employed (in thousands) & 180 & 93.376 & 76.510 & 6.205 & 272.938 \\
\hline Number of employees (in thousands) & 180 & 424.224 & 411.343 & 27.054 & 1672.778 \\
\hline Number of company dissolution, revocation and & & & & & \\
termination & 180 & 1772.661 & 2890.988 & 9.000 & 17878.000 \\
\hline Number of companies registered & 180 & 29841.780 & 43896.450 & 483.000 & 167623.000 \\
\hline Total registered capital (billion TWD) & 180 & 921.385 & 2007.655 & 3.801 & 10118.780 \\
\hline Total consumption of electricity (MWh) & 180 & 6352.144 & 6538.277 & 152.000 & 22351.000 \\
\hline Total amount of business sales (billion TWD) & 180 & 1745.710 & 2708.101 & 19.613 & 13126.300 \\
\hline
\end{tabular}

Table 1: Basic statistics for variables

\section{The Results}

\subsection{The Overall Efficiency: Entrepreneurship System}

Figure 2 shows the overall efficiency of each county and city in Taiwan. We find that New Taipei and Taipei City are the most efficient cities and that Taitung County is the most efficient county in terms of entrepreneurship systems, because their overall efficiency is 1 . On the other hand, Hualien, Yilan, and Chiayi County are the least efficient administrative areas. The average overall performance is 0.54 .

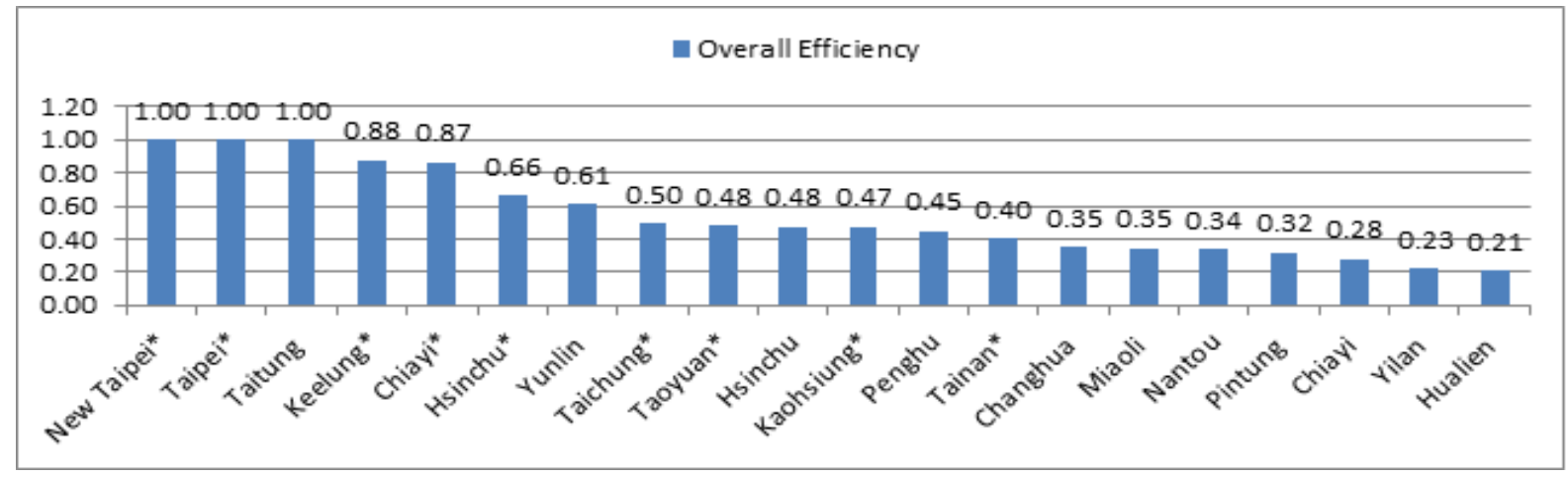

Note: A name with an asterisk * indicates that it is a city.

Figure 2: Overall efficiency of each county and city in Taiwan

We further investigate whether an urban-rural gap exists between the efficiency scores by testing the significance of the differences in their group means. Since the counties in Taiwan 
are underdeveloped and less crowded than the cities, they are often considered rural areas. Therefore, comparing the differences between the mean scores of the counties and cities can be considered a test for the existence of an urban-rural gap. We apply the Wilcoxon (MannWhitney) test to investigate the significance of this gap. The $2^{\text {nd }}$ row in Table 2 shows the test results. They indicate that the urban-rural gap is significant for the performance of entrepreneurship systems between the urban and rural groups of Taiwan's counties/cities, and that the efficiencies of counties and cities in the urban group are higher than the efficiencies of those in the rural group. We also show the results of t-tests for reference.

We further compare the differences in the means between service and not-service business types in counties and cities. To test this difference in the means, we categorize the counties/cities as service or not-service types by sorting them according to the proportion of employment in the service sector. A county/city with a higher proportion of employment in the service sector than this threshold value is categorized as a service-type county/city. Otherwise, it is regarded as a not-service-type county/city. The Wilcoxon (Mann-Whitney) test is also applied here. The $3^{\text {rd }}$ row in Table 2 shows the test results. They indicate that there is no significant gap in the performance of the entrepreneurship system between the groups of Taiwan's service and notservice counties/cities, with the result of the t-test showing that this is significant at the $90 \%$ level.

\begin{tabular}{|l|c|c|c|}
\hline \multicolumn{1}{|c|}{ Characteristic } & Wilcoxon (Mann-Whitney) test & t-test & Kruskal-Wallis test \\
\hline Urban/Rural & $\mathrm{z}=-2.625^{* *}(0.0087)$ & $0.2778^{* *}(0.0161)$ & - \\
\hline $\begin{array}{l}\text { Service/Not- } \\
\text { Service }\end{array}$ & $\mathrm{z}=-1.389(0.1649)$ & $0.2361^{*}(0.0569)$ & - \\
\hline Among Area & - & - & $X^{2}(3)=3.027(0.3874)$ \\
\hline
\end{tabular}

Note: ${ }^{* *}$ represents a $95 \%$ significance level; ${ }^{*}$ represents a $90 \%$ significance level.

The values in parentheses are the probabilities of the test results.

\section{Table 2: Test results of overall efficiency}

Finally, we test the effects of location on the average efficiency scores in Taiwan's counties and cities. The "Strategic Plan for National Spatial Development" proposed by the National Development Council in Taiwan's Executive Yuan in 2010 divides Taiwan's counties and cities into north, central, south, and east regions. We categorize our counties and cities according to this definition and test for differences in the overall efficiency among the regions using the Kruskal-Wallis test. The $4^{\text {th }}$ row in Table 2 shows the test results. They show that there is no significant difference in the performance of entrepreneurship systems among the regional groups of Taiwan's service and not-service counties and cities.

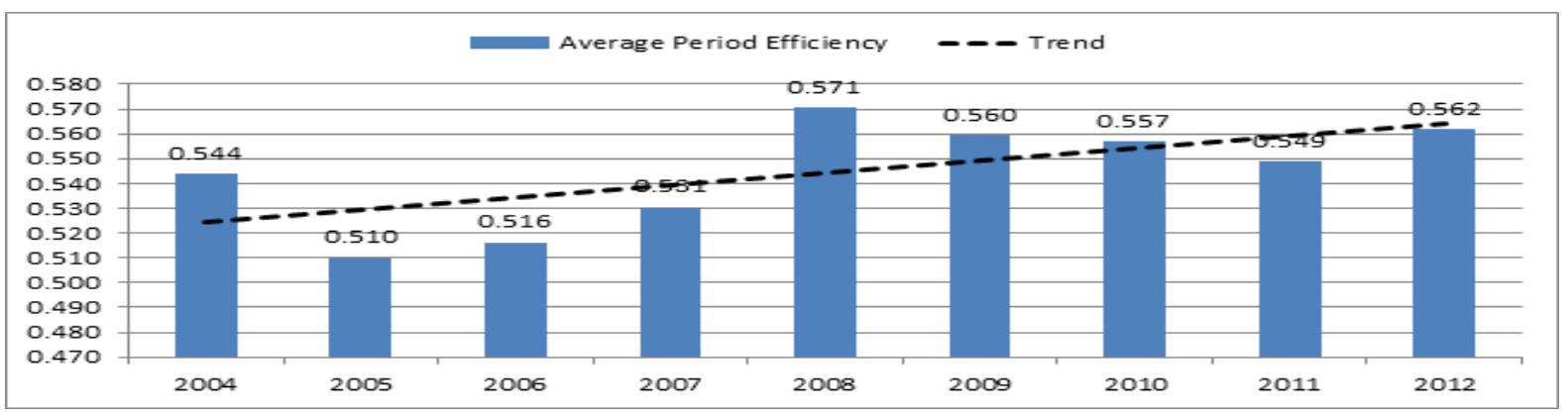

Figure 3: Average period efficiency of Taiwan's counties/cities 2004-2012 


\begin{tabular}{|c|c|c|c|c|c|}
\hline Year & Obs. & Characteristic & $\begin{array}{c}\text { Wilcoxon } \\
\text { (Mann-Whitney) test }\end{array}$ & t-test & Kruskal-Wallis test \\
\hline \multirow{3}{*}{2004} & \multirow{3}{*}{20} & Urban/Rural & $\mathrm{z}=-2.550^{* *}(0.011)$ & $0.3045 * *(0.009)$ & - \\
\hline & & $\begin{array}{l}\text { Service/Not- } \\
\text { Service } \\
\end{array}$ & $\mathrm{z}=-1.389(0.165)$ & $0.2298 *(0.073)$ & - \\
\hline & & Area & - & - & $X^{2}(3)=3.011(0.390)$ \\
\hline \multirow{3}{*}{2005} & \multirow{3}{*}{20} & Urban/Rural & $\mathrm{z}=-2.625^{* *}(0.009)$ & $0.2793 * *(0.023)$ & - \\
\hline & & $\begin{array}{l}\text { Service/Not- } \\
\text { Service } \\
\end{array}$ & $\mathrm{z}=-1.548(0.122)$ & $0.26458^{* *}(0.042)$ & - \\
\hline & & Area & - & - & $X^{2}(3)=3.099(0.377)$ \\
\hline \multirow{3}{*}{2006} & \multirow{3}{*}{20} & Urban/Rural & $\mathrm{z}=-2.625^{* *}(0.009)$ & $0.2601^{* *}(0.027)$ & - \\
\hline & & $\begin{array}{l}\text { Service/Not- } \\
\text { Service } \\
\end{array}$ & $\mathrm{z}=-1.627(0.104)$ & $0.2318 *(0.063)$ & - \\
\hline & & Area & - & - & $X^{2}(3)=3.176(0.365)$ \\
\hline \multirow{3}{*}{2007} & \multirow{3}{*}{20} & Urban/Rural & $\mathrm{z}=-2.625^{* *}(0.009)$ & $0.2006^{* *}(0.023)$ & - \\
\hline & & $\begin{array}{l}\text { Service/Not- } \\
\text { Service }\end{array}$ & $\mathrm{z}=-1.468(0.142)$ & $0.2298 *(0.073)$ & - \\
\hline & & Area & - & - & $X^{2}(3)=3.176(0.365)$ \\
\hline \multirow{3}{*}{2008} & \multirow{3}{*}{20} & Urban/Rural & $\mathrm{z}=-1.864 *(0.062)$ & $0.2376^{* *}(0.038)$ & - \\
\hline & & $\begin{array}{l}\text { Service/Not- } \\
\text { Service } \\
\end{array}$ & $\mathrm{z}=-1.706^{*}(0.088)$ & $0.2145^{*}(0.077)$ & - \\
\hline & & Area & - & - & $X^{2}(3)=2.186(0.535)$ \\
\hline \multirow{3}{*}{2009} & \multirow{3}{*}{20} & Urban/Rural & $\mathrm{z}=-2.245^{* *}(0.025)$ & $0.2426 * *(0.034)$ & - \\
\hline & & $\begin{array}{l}\text { Service/Not- } \\
\text { Service } \\
\end{array}$ & $\mathrm{z}=-1.706^{*}(0.088)$ & $0.2457^{* *}(0.041)$ & - \\
\hline & & Area & - & - & $X^{2}(3)=2.790(0.425)$ \\
\hline \multirow{3}{*}{2010} & \multirow{3}{*}{20} & Urban/Rural & $\mathrm{z}=-2.397 * *(0.017)$ & $0.2771 * *(0.017)$ & - \\
\hline & & $\begin{array}{l}\text { Service/Not- } \\
\text { Service }\end{array}$ & $\mathrm{z}=-1.627(0.104)$ & $0.2394 *(0.055)$ & - \\
\hline & & Area & - & - & $X^{2}(3)=3.042(0.385)$ \\
\hline \multirow{3}{*}{2011} & \multirow{3}{*}{20} & Urban/Rural & $\mathrm{z}=-2.397^{* *}(0.017)$ & $0.2788 * *(0.018)$ & - \\
\hline & & $\begin{array}{l}\text { Service/Not- } \\
\text { Service }\end{array}$ & $\mathrm{z}=-1.905^{*}(0.057)$ & $0.2520 * *(0.044)$ & - \\
\hline & & Area & - & - & $X^{2}(3)=2.732(0.435)$ \\
\hline \multirow{3}{*}{2012} & \multirow{3}{*}{20} & Urban/Rural & $\mathrm{z}=-2.245 * *(0.025)$ & $0.2650 * *(0.023)$ & - \\
\hline & & $\begin{array}{l}\text { Service/Not- } \\
\text { Service }\end{array}$ & $\mathrm{z}=-1.865^{*}(0.062)$ & $0.2576^{* *}(0.036)$ & - \\
\hline & & Area & - & - & $X^{2}(3)=2.275(0.517)$ \\
\hline \begin{tabular}{|l|} 
Yearly \\
Mean
\end{tabular} & 9 & Before/After 2008 & $\mathrm{z}=-2.449^{* *}(0.014)$ & $0.0346^{* *}(0.003)$ & - \\
\hline
\end{tabular}

Note: ** represents a $95 \%$ significance level; * represents a $90 \%$ significance level.

The values in parentheses are the probabilities of the test results.

The number 3 in parentheses after $X^{2}$ is the degree of freedom (d.f.).

Table 3: Test results of period efficiencies 


\subsection{The Period Efficiency}

We further calculate the period efficiency in (6) and show the average period efficiency of entrepreneurship systems in Taiwan's counties and cities in Figure 3. The results indicate that the period efficiency on average rose steadily from 2005 to 2008, but fell gradually after 2008, except in 2012. However, the trend line shows that the period efficiency of the entrepreneurship system is improving. These results show that among Taiwan's counties and cities, only New Taipei City, Taipei City, and Taitung County are efficient in every year.

We then test the significance of the urban-rural gap, service and not-service gap, regional differences of each year, and the differences before and after 2008 for the period efficiency. The test results are shown in Table 3. From the results, we find that the urban-rural gap exists in all research years, but the service and not-service gap only exists in the years 2008-2009 and 2011-2012. However, the regional difference is not significant in all years. Finally, there exists a significant difference before and after 2008 for the average period efficiency of Taiwan's counties and cities. To sum up, the urban-rural gaps in period efficiency exist in all research years; and its means after 2008 are significantly higher than the means before 2008 in Taiwan's counties and cities.

\begin{tabular}{|l|c|c|c|c|}
\hline County/City & Area & Entrepreneurship & Survival & Operation \\
\hline New Taipei City & North & 1.000 & 1.000 & 1.000 \\
\hline Taipei City & North & 1.000 & 1.000 & 1.000 \\
\hline Taoyuan City & North & 0.971 & 0.959 & 0.222 \\
\hline Taichung City & Middle & 1.000 & 1.000 & 0.229 \\
\hline Tainan City & South & 1.000 & 1.000 & 0.180 \\
\hline Kaohsiung City & South & 1.000 & 1.000 & 0.227 \\
\hline Yilan County & North & 1.000 & 1.000 & 0.099 \\
\hline Hsinchu County & North & 0.834 & 0.886 & 0.244 \\
\hline Miaoli County & Middle & 0.924 & 0.987 & 0.149 \\
\hline Changhua County & Middle & 1.000 & 1.000 & 0.163 \\
\hline Nantou County & Middle & 1.000 & 1.000 & 0.175 \\
\hline Yunlin County & Middle & 1.000 & 1.000 & 0.378 \\
\hline Chiayi County & South & 1.000 & 1.000 & 0.135 \\
\hline Pintung County & South & 0.940 & 0.978 & 0.177 \\
\hline Taitung County & East & 1.000 & 1.000 & 1.000 \\
\hline Hualien County & East & 0.952 & 0.922 & 0.088 \\
\hline Penghu County & South & 0.763 & 0.939 & 0.297 \\
\hline Keelung City & North & 0.640 & 0.997 & 1.000 \\
\hline Hsinchu City & North & 0.745 & 0.945 & 0.451 \\
\hline Chiayi City & South & 0.811 & 0.964 & 0.860 \\
\hline & & 0.929 & 0.979 & 0.404 \\
\hline
\end{tabular}

Table 4: Stage efficiencies of Taiwan's counties and cities 


\subsection{The Stage Efficiencies}

We also calculate the stage efficiencies for each county and city in Taiwan based on equations (7)-(9) and list them in Table 4. We find first that most counties and cities are efficient at entrepreneurship and survival stage. Only New Taipei City, Taipei City, Taitung County, and Keelung City are efficient at operation stage. Among these, only New Taipei City, Taipei City, and Taitung County are efficient at all three stages. Finally, the average values of each stage efficiency show that the performance of the survival stage is higher than that of the administration and operation stages. This low performance at the operation stage is also the main source influencing the overall efficiency performance. We then test the significance of the urban-rural gap, service and not-service gap, and the regional differences in each stage's efficiency. The test results are shown in Table 5. The findings indicate that only the urbanrural gap and service and not-service gap exist for efficiencies at the operation stage in Taiwan's counties/cities.

\begin{tabular}{|l|c|c|c|c|c|c|}
\hline \multirow{2}{*}{ Characteristics } & \multicolumn{2}{|c|}{ Entrepreneurship } & \multicolumn{2}{c|}{ Survival } & \multicolumn{2}{c|}{ Operation } \\
\cline { 2 - 7 } & $\begin{array}{c}\text { Wilcoxon } \\
\text { testZ(Pr) }\end{array}$ & $\begin{array}{c}\text { K.-W. test } \\
X^{2}(3)(\mathrm{Pr})\end{array}$ & $\begin{array}{c}\text { Wilcoxon } \\
\text { test } \\
\mathrm{Z}(\mathrm{Pr})\end{array}$ & $\begin{array}{c}\text { K.-W. test } \\
X^{2}(3)(\mathrm{Pr})\end{array}$ & $\begin{array}{c}\text { Wilcoxon test } \\
\mathrm{Z}(\mathrm{Pr})\end{array}$ & $\begin{array}{c}\text { K.-W. test } \\
X^{2}(3)(\mathrm{Pr})\end{array}$ \\
\hline Urban/Rural & $0.291(0.77)$ & - & $-0.374(0.71)$ & - & $-2.288^{* *}(0.02)$ & - \\
\hline $\begin{array}{l}\text { Service/Not- } \\
\text { Service }\end{array}$ & $1.084(0.28)$ & - & $0.737(0.46)$ & - & $-1.750^{*}(0.08)$ & - \\
\hline Area & - & $1.715(0.66)$ & - & $1.989(0.58)$ & - & $2.729(0.44)$ \\
\hline
\end{tabular}

Note: ${ }^{* *}$ represents a $95 \%$ significance level; ${ }^{*}$ represents a $90 \%$ significance level; values in parentheses are the probabilities of the test results; K.-W. stands for Kruskal-Wallis; the number 3 in parentheses after $X^{2}$ is the degree of freedom (d.f.).

Table 5: Test results of stage efficiencies

\subsection{Stage Efficiencies for Each Period}

We also calculate the stage efficiencies for each period defined by equations (10)-(12) in section 3.4. We then calculated their average values by stages for each year. Figure 4 shows the trends of these average values. According to Figure 4, we find that the performance at survival stage is always higher than the performances at entrepreneurship and operation stages. However, from the trend lines of each stage, the performances at entrepreneurship and survival stage worsen gradually; the amplitude at entrepreneurship stage is more obvious than that of survival stage. However the performances at operation stage are improving gradually. 


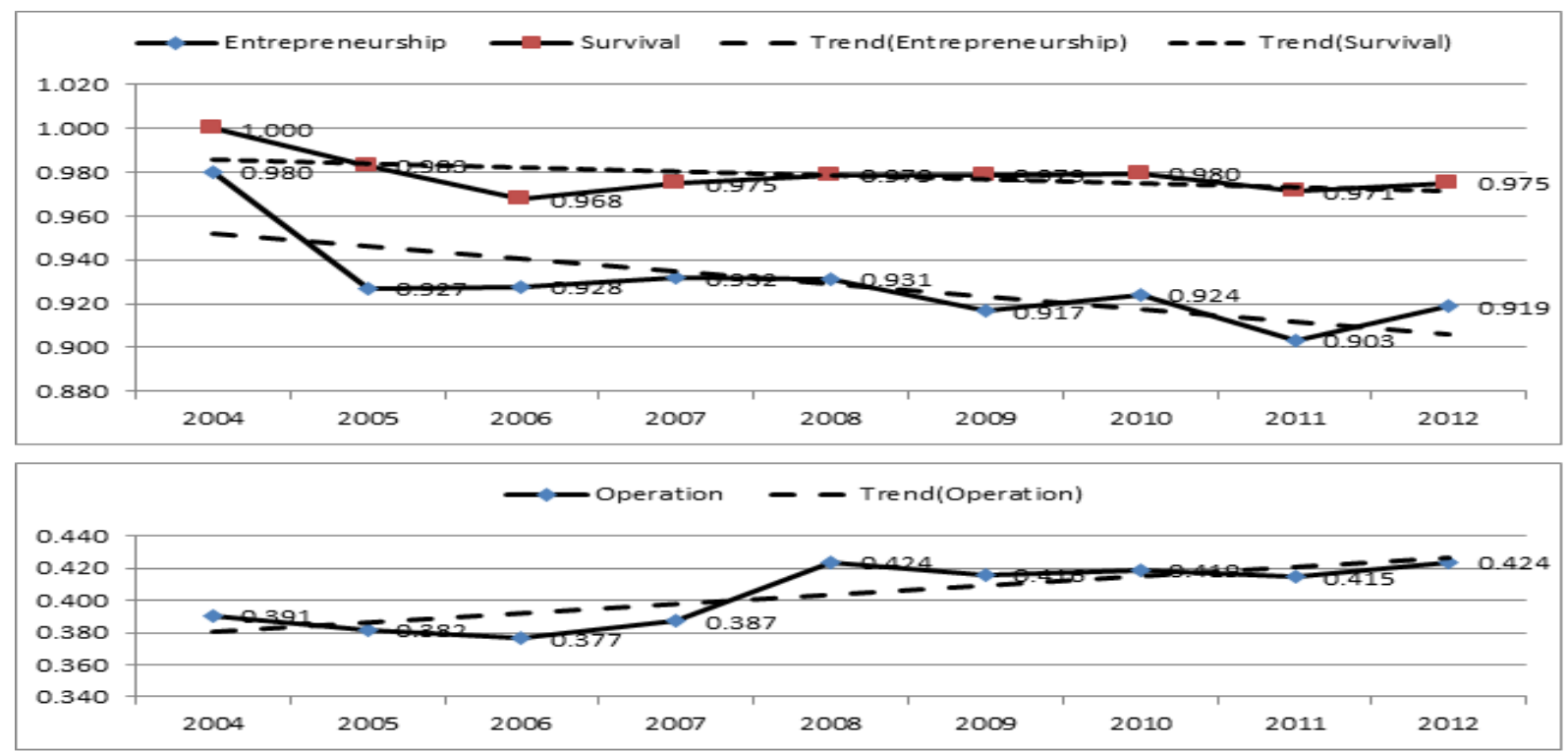

Figure 4: Average stage efficiencies of Taiwan's counties and cities 2004-2012

Finally, we test the significance of the urban-rural gap, service and not-service gap, and regional differences of each year, and the differences before and after 2008 for the stage efficiencies. The test results are shown in Table 6. From the results, we find that the urbanrural gap exists in all research years, while the service and not-service gap exists in years 20052006 and 2008-2012 at operation stage. However, the regional differences are not significant at all stages in all years. Finally, significant differences exist before and after 2008 for the average entrepreneurship and operation stage efficiency of Taiwan's counties and cities (last row in Table 6). However, the signs of their test results are opposite. The positive sign at entrepreneurship stage implies that the average performance before 2008 is better than the after; the negative sign at operation stage implies that the average performance before 2008 is worse than after. To sum up, the urban-rural gaps of average efficiency at entrepreneurship stage exist in all research years and the average performance at entrepreneurship and operation stage are significantly different before and after 2008 in Taiwan's counties and cities.

\begin{tabular}{|c|c|c|c|c|c|c|c|c|}
\hline \multirow[b]{2}{*}{ Year } & \multirow[b]{2}{*}{ Obs } & \multirow[b]{2}{*}{ Features } & \multicolumn{2}{|c|}{ Entrepreneurship } & \multicolumn{2}{|c|}{ Survival } & \multicolumn{2}{|c|}{ Operation } \\
\hline & & & $\begin{array}{l}\text { Wilcoxon } \\
\text { testZ }(\mathrm{Pr})\end{array}$ & $\begin{array}{l}\text { K.-W. test } \\
X^{2}(3)(\mathrm{Pr})\end{array}$ & $\begin{array}{l}\text { Wilcoxon } \\
\text { testZ }(\mathrm{Pr})\end{array}$ & $\begin{array}{l}\text { K.-W. test } \\
X^{2}(3)(\mathrm{Pr})\end{array}$ & $\begin{array}{l}\text { Wilcoxon } \\
\text { testZ }(\mathrm{Pr})\end{array}$ & $\begin{array}{l}\text { K.-W. test } \\
X^{2}(3)(\operatorname{Pr})\end{array}$ \\
\hline \multirow{3}{*}{2004} & \multirow{3}{*}{20} & Urban/Rural & $\begin{array}{c}1.604 \\
(0.109)\end{array}$ & - & $\begin{array}{c}1.106 \\
(0.269)\end{array}$ & - & $\begin{array}{c}-2.364^{* *} \\
(0.018) \\
\end{array}$ & - \\
\hline & & $\begin{array}{l}\text { Service/Not- } \\
\text { Service } \\
\end{array}$ & $\begin{array}{l}1.977^{* *} \\
(0.048)\end{array}$ & - & $\begin{array}{c}1.363 \\
(0.173) \\
\end{array}$ & - & $\begin{array}{l}-1.591 \\
(0.112) \\
\end{array}$ & - \\
\hline & & Area & - & $\begin{array}{c}0.308 \\
(0.959) \\
\end{array}$ & - & $\begin{array}{c}0.333 \\
(0.954) \\
\end{array}$ & - & $\begin{array}{c}2.554 \\
(0.466) \\
\end{array}$ \\
\hline \multirow{3}{*}{2005} & \multirow{3}{*}{20} & Urban/Rural & $\begin{array}{c}0.422 \\
(0.673) \\
\end{array}$ & - & $\begin{array}{r}-0.045 \\
(0.964) \\
\end{array}$ & - & $\begin{array}{c}-2.135^{* *} \\
(0.033) \\
\end{array}$ & - \\
\hline & & $\begin{array}{l}\text { Service/Not- } \\
\text { Service }\end{array}$ & $\begin{array}{c}1.124 \\
(0.261)\end{array}$ & - & $\begin{array}{c}1.348 \\
(0.178)\end{array}$ & - & $\begin{array}{c}-1.750^{*} \\
(0.080)\end{array}$ & - \\
\hline & & Area & - & $\begin{array}{r}1.395 \\
(0.707) \\
\end{array}$ & - & $\begin{array}{r}0.988 \\
(0.804) \\
\end{array}$ & - & $\begin{array}{c}3.205 \\
(0.361)\end{array}$ \\
\hline
\end{tabular}




\begin{tabular}{|c|c|c|c|c|c|c|c|c|}
\hline \multirow{3}{*}{2006} & \multirow{3}{*}{20} & Urban/Rural & $\begin{array}{c}1.218 \\
(0.223) \\
\end{array}$ & - & $\begin{array}{c}0.312 \\
(0.755)\end{array}$ & - & $\begin{array}{c}-2.135^{* *} \\
(0.033) \\
\end{array}$ & - \\
\hline & & $\begin{array}{l}\text { Service/Not- } \\
\text { Service }\end{array}$ & $\begin{array}{c}1.026 \\
(0.305)\end{array}$ & - & $\begin{array}{c}1.255 \\
(0.209)\end{array}$ & - & $\begin{array}{c}-1.829^{*} \\
(0.067)\end{array}$ & - \\
\hline & & Area & - & $\begin{array}{r}3.437 \\
(0.329) \\
\end{array}$ & - & $\begin{array}{c}3.165 \\
(0.367) \\
\end{array}$ & - & $\begin{array}{r}3.153 \\
(0.369) \\
\end{array}$ \\
\hline \multirow{3}{*}{2007} & \multirow{3}{*}{20} & Urban/Rural & $\begin{array}{c}0.936 \\
(0.349) \\
\end{array}$ & - & $\begin{array}{l}-0.312 \\
(0.755)\end{array}$ & - & $\begin{array}{c}-2.404^{* *} \\
(0.016)\end{array}$ & - \\
\hline & & \begin{tabular}{|l} 
Service/Not- \\
Service
\end{tabular} & $\begin{array}{c}0.883 \\
(0.377) \\
\end{array}$ & - & $\begin{array}{c}0.325 \\
(0.745) \\
\end{array}$ & - & $\begin{array}{l}-1.632 \\
(0.103) \\
\end{array}$ & - \\
\hline & & Area & - & $\begin{array}{c}2.327 \\
(0.507) \\
\end{array}$ & - & $\begin{array}{c}0.960 \\
(0.811) \\
\end{array}$ & - & $\begin{array}{r}3.626 \\
(0.305) \\
\end{array}$ \\
\hline \multirow{3}{*}{2008} & \multirow{3}{*}{20} & Urban/Rural & $\begin{array}{c}0.422 \\
(0.673) \\
\end{array}$ & - & $\begin{array}{l}-0.749 \\
(0.454)\end{array}$ & - & $\begin{array}{c}-1.754^{*} \\
(0.079) \\
\end{array}$ & - \\
\hline & & $\begin{array}{l}\text { Service/Not- } \\
\text { Service }\end{array}$ & $\begin{array}{c}0.928 \\
(0.353)\end{array}$ & - & $\begin{array}{c}0.830 \\
(0.406)\end{array}$ & - & $\begin{array}{c}-1.750^{*} \\
(0.080)\end{array}$ & - \\
\hline & & Area & - & $\begin{array}{c}1.227 \\
(0.747)\end{array}$ & - & $\begin{array}{c}0.532 \\
(0.912)\end{array}$ & - & $\begin{array}{r}2.439 \\
(0.486) \\
\end{array}$ \\
\hline \multirow{3}{*}{2009} & \multirow{3}{*}{20} & Urban/Rural & $\begin{array}{c}0.134 \\
(0.894) \\
\end{array}$ & - & $\begin{array}{l}-0.843 \\
(0.399) \\
\end{array}$ & - & $\begin{array}{c}-2.289^{* *} \\
(0.022) \\
\end{array}$ & - \\
\hline & & $\begin{array}{l}\text { Service/Not- } \\
\text { Service }\end{array}$ & $\begin{array}{c}1.534 \\
(0.125) \\
\end{array}$ & - & $\begin{array}{c}1.026 \\
(0.305) \\
\end{array}$ & - & $\begin{array}{c}-1.790^{*} \\
(0.073) \\
\end{array}$ & - \\
\hline & & Area & - & $\begin{array}{c}0.884 \\
(0.829) \\
\end{array}$ & - & $\begin{array}{c}0.930 \\
(0.818) \\
\end{array}$ & - & $\begin{array}{r}3.329 \\
(0.344) \\
\end{array}$ \\
\hline \multirow{3}{*}{2010} & \multirow{3}{*}{20} & Urban/Rural & $\begin{array}{c}0.936 \\
(0.349) \\
\end{array}$ & - & $\begin{array}{l}-0.312 \\
(0.755)\end{array}$ & - & $\begin{array}{c}-2.335^{* *} \\
(0.020)\end{array}$ & - \\
\hline & & $\begin{array}{l}\text { Service/Not- } \\
\text { Service } \\
\end{array}$ & $\begin{array}{c}0.883 \\
(0.377) \\
\end{array}$ & - & $\begin{array}{l}-0.046 \\
(0.963) \\
\end{array}$ & - & $\begin{array}{c}-1.876^{*} \\
(0.061) \\
\end{array}$ & - \\
\hline & & Area & - & $\begin{array}{c}3.816 \\
(0.282) \\
\end{array}$ & - & $\begin{array}{c}2.750 \\
(0.432) \\
\end{array}$ & - & $\begin{array}{c}2.621 \\
(0.454) \\
\end{array}$ \\
\hline \multirow{3}{*}{2011} & \multirow{3}{*}{20} & Urban/Rural & $\begin{array}{c}0.374 \\
(0.708) \\
\end{array}$ & - & $\begin{array}{l}-0.129 \\
(0.898) \\
\end{array}$ & - & $\begin{array}{c}-2.335^{* *} \\
(0.020) \\
\end{array}$ & - \\
\hline & & $\begin{array}{l}\text { Service/Not- } \\
\text { Service }\end{array}$ & $\begin{array}{c}1.258 \\
(0.209)\end{array}$ & - & $\begin{array}{l}-0.045 \\
(0.964)\end{array}$ & - & $\begin{array}{c}-1.797^{*} \\
(0.072)\end{array}$ & - \\
\hline & & Area & - & $\begin{array}{c}1.913 \\
(0.591)\end{array}$ & - & $\begin{array}{c}1.484 \\
(0.686)\end{array}$ & - & $\begin{array}{c}3.004 \\
(0.391) \\
\end{array}$ \\
\hline \multirow{3}{*}{2012} & \multirow{3}{*}{20} & Urban/Rural & $\begin{array}{c}0.686 \\
(0.493) \\
\end{array}$ & - & $\begin{array}{l}-0.134 \\
(0.894) \\
\end{array}$ & - & $\begin{array}{c}-2.335^{* *} \\
(0.020) \\
\end{array}$ & - \\
\hline & & $\begin{array}{l}\text { Service/Not- } \\
\text { Service }\end{array}$ & $\begin{array}{c}1.342 \\
(0.180) \\
\end{array}$ & - & $\begin{array}{c}0.511 \\
(0.609) \\
\end{array}$ & - & $\begin{array}{c}-1.876^{*} \\
(0.061) \\
\end{array}$ & - \\
\hline & & Area & - & $\begin{array}{c}3.290 \\
(0.349) \\
\end{array}$ & - & $\begin{array}{c}2.602 \\
(0.457) \\
\end{array}$ & - & $\begin{array}{r}2.536 \\
(0.469) \\
\end{array}$ \\
\hline $\begin{array}{l}\text { Yearly } \\
\text { Means }\end{array}$ & 9 & $\begin{array}{l}\text { Before/After } \\
2008\end{array}$ & $\begin{array}{l}1.960^{* *} \\
(0.050)\end{array}$ & - & $\begin{array}{c}0.246 \\
(0.806)\end{array}$ & - & $\begin{array}{c}-2.449^{* *} \\
(0.014)\end{array}$ & - \\
\hline
\end{tabular}

Note: ${ }^{* *}$ represents a $95 \%$ significance level; ${ }^{*}$ represents a $90 \%$ significance level; values in parentheses are the probabilities of the test results; K.-W. stands for Kruskal-Wallis; the number 3 in parentheses after $X^{2}$ is the degree of freedom (d.f.). 


\subsection{The Dynamic Self-Effects of Each Efficiency}

To investigate the influence of the efficiency in the previous time period on the efficiency in the present period, we implement the dynamic panel data model using the system generalized method of moments (system GMM) approach used by Arellano and Bover [1] and Blundell and Bond[4]. We include the efficient scores of one lagged period in the models. Table 7 shows the empirical results. Accordingly, we can find that the estimated coefficients of the lagged variable are positive and significant, which means that dynamic self-effects exist for each stage's performance and the period efficiency. In other words, the present efficiencies in the entrepreneurship system of Taiwan's counties and cities are positively influenced by the performance in the previous period.

\begin{tabular}{|l|c|c|c|c|c|c|c|c|}
\hline \multirow{2}{*}{ Variables } & Entrepreneurship & \multicolumn{2}{c|}{ Survival } & \multicolumn{2}{c|}{ Operation } & \multicolumn{2}{c|}{ Period } \\
\cline { 2 - 9 } & Coef. & z-value & Coef. & z-value & Coef. & z-value & Coef. & z-value \\
\hline Lag 1. & $0.296^{* *}$ & 3.74 & $0.210^{* *}$ & 2.26 & $0.433^{* *}$ & 4.68 & $0.357^{* *}$ & 3.88 \\
\hline Urban & $0.236^{* *}$ & 3.38 & 0.078 & 0.85 & $0.224^{* *}$ & 3.82 & -0.176 & -1.37 \\
\hline Service & -0.025 & -0.18 & $-0.156^{* *}$ & -3.41 & 0.100 & 1.17 & $0.242^{* *}$ & 2.57 \\
\hline North & $-0.263^{* *}$ & -2.94 & $-0.212^{* *}$ & -3.03 & 0.135 & 0.32 & $5.505^{* *}$ & 2.43 \\
\hline Middle & 0.028 & 0.14 & -0.071 & -0.95 & 0.070 & 0.22 & $2.016^{* *}$ & 2.22 \\
\hline South & -0.139 & -1.07 & $-0.125^{*}$ & -1.86 & 0.113 & 0.37 & $3.770^{* *}$ & 2.36 \\
\hline After2008 & -0.001 & -0.22 & 0.003 & 0.59 & $0.021^{* *}$ & 2.57 & $0.031^{* *}$ & 5.14 \\
\hline Constant & $0.678^{* *}$ & 3.52 & $0.918^{* *}$ & 9.48 & -0.016 & -0.05 & $-3.235^{* *}$ & -2.24 \\
\hline Wald $X^{2}(7)$ & $158.38(0.000)$ & $36.33(0.000)$ & $364.39(0.000)$ & $343.14(0.000)$ \\
\hline
\end{tabular}

Note: ${ }^{* *}$ represents a $95 \%$ significance level; ${ }^{*}$ represents a $90 \%$ significance level; values in parentheses of Wald tests are the probabilities of the test results.

Table 7: Estimated results of dynamic panel data model (system GMM)

\section{Conclusions and Discussion}

In this study, we propose a method to measure the efficiency level of the whole entrepreneurship system, comprising the three stages of entrepreneurship, survival, and operation. By employing the DNDEA model with SBM, we evaluate the entrepreneurship system in Taiwan's counties and cities over the period 2004-2012. One contribution of this study is that it is the first to extend the application of DNDEA to regional studies for the evaluation of the performance of regional entrepreneurship systems.

Our evaluated results show first that in terms of overall efficiency in entrepreneurship systems in Taiwan, New Taipei and Taipei City are the most efficient cities and Taitung County is the most efficient county. The results of Wilcoxon (Mann-Whitney) tests indicate that the urbanrural gap is significant for the performance of entrepreneurship systems between the urban and rural group of counties and cities. Second, we find that New Taipei City, Taipei City, and Taitung County are efficient in every period. The trend of average period efficiency of the entrepreneurship system in Taiwan's counties and cities is improving, although it falls after 2008 after gradually rising from 2005 to 2008. The significant difference before and after 2008 for the average period efficiency of Taiwan's counties and cities implies that the means after 
2008 are significantly higher than the means before 2008. Third, as for the stage efficiencies, again, New Taipei City, Taipei City, and Taitung County are always efficient in every stage. The average values of the survival stage are always higher than those of the administration and operation stages. The results of Wilcoxon (Mann-Whitney) tests reveal that only urban-rural and service and not-service gaps exist for the efficiencies at operation stage in Taiwan's counties and cities. Finally, the trend line for the performance at operation stage shows that it is improving gradually.

From the findings above, the first implication for local governments in Taiwan is that policies should derive from the perspective of the overall entrepreneurship system, not from any stage alone. In the present situation, our findings show that resources should be used to improve the performance at operation stage in Taiwan's local governments, because it is always lower than the performances at entrepreneurship and survival stages, even though it is improving in the long run. Second, for the central government, the urban-rural gap in the performance of the entrepreneurship system is another important social issue, especially for the gaps at the operation stage in every year. The superior performance in the urban areas at this stage might be due to density and scale economies; dynamic self-effects might then reinforce these economies in the next period. A vicious circle at the operation stage in a rural region could be set in motion. Finding ways to solve this problem is always important for Taiwan's government. Finally, entrepreneurs should locate their new start-ups in urban areas in Taiwan, due to the higher efficiencies of the entrepreneurship system and the superior environment for business operation.

For future studies, the systemic approach underlying the analytical framework in this study can be applied to other administration systems in local government, such as social welfare, education, or social security, as mentioned in Chen [6].

\section{References}

[1]Arellano, M., and Bover, O. (1995), Another Look at the Instrumental Variable Estimation of Error-Components Models, Journal of Econometrics 68: 1, 29-51.

[2] Avkiran, N. K.(2015), An illustration of dynamic network DEA in commercial banking including robustness tests, Omega 55, 141-150.

[3] Bai, X.-J., Yan, W.-K., and Chiu, Y.-H.(2015), Performance evaluation of China's Hi-tech zones in the post financial crisis era-Analysis based on the dynamic network SBM model, China Economic Review 34, 122-134.

[4]Blundell, R., and Bond, S. (1998), Initial Conditions and Moment Restrictions in Dynamic Panel Data Models, Journal of Econometrics 87: 1, 115-143

[5] Chang, Y.-T., Park, H., Zou, B., and Kafle, N.(2016), Passenger facility charge vs. airport improvement program funds: A dynamic network DEA analysis for U.S. airport financing, Transportation Research Part E: Logistics and Transportation Review 88, 76-93.

[6] Chen, C. C.(2017), Measuring departmental and overall regional performance: applying the multi-activity DEA model to Taiwan's cities/counties, Omega 67, 60-80.

[7] Färe, R., and Grosskopf, S. (1996), Intertemporal production frontiers: with dynamic DEA, Boston: Kluwer Academic Publishers. 
[8]GAMS Development Corporation (2016), General Algebraic Modeling System (GAMS) Release 24.8.1. Washington, DC, USA.

[9] Herrera-Restrepo, O., Triantis, K., Trainor, J., Murray-Tuite, P., and Edara, P.(2016), A multi-perspective dynamic network performance efficiency measurement of an evacuation: A dynamic network-DEA approach, Omega 60, 45-59.

[10] Kao, C.(2014), Efficiency decomposition in network data envelopment analysis with slacksbased measures, Omega 45, 1-6.

[11] Khushalani, J., and Ozcan, Y. A.(2017), Are hospitals producing quality care efficiently? An analysis using Dynamic Network Data Envelopment Analysis (DEA), forthcoming in Socio-Economic Planning Sciences.

[12] Organization for Economic Co-operation and Development(OECD) (2016), Entrepreneurship at a Glance 2016, OECD Publishing, Paris. DOI: http://dx.doi.org/10.1787/entrepreneur_aag-2016-en. [Accessed 13/07/2016]

[13] Olfat, L., Amiri, M., Soufi, J. B., and Pishdar, M.(2016), A dynamic network efficiency measurement of airports performance considering sustainable development concept: A fuzzy dynamic network-DEA approach, Journal of Air Transport Management 57, 272-290.

[14] Omrani, H., and Soltanzadeh, E.(2016), Dynamic DEA models with network structure: An application for Iranian airlines, Journal of Air Transport Management 57, 52-61.

[15] Schumpeter, J. A.(1947), The creative response in economic history, The Journal of Economic History 7: 2, 149-59.

[16] Tone, K.(2001), A slacks-based measure of efficiency in data envelopment analysis, European Journal of Operational Research 130: 3, 498-509.

[17] Tone, K., and Tsutsui, M.(2010), Dynamic DEA: A slacks-based measure approach, Omega 38: 3-4, 145-156.

[18] Tone, K., and Tsutsui, M.(2014), Dynamic DEA with network structure: A slacks-based measure approach, Omega 42: 1, 124-131.

[19] Tone, K., and Tsutsui. M.(2009), Network DEA: A slacks-based measure approach, European Journal of Operational Research 197:1, 243-252. 